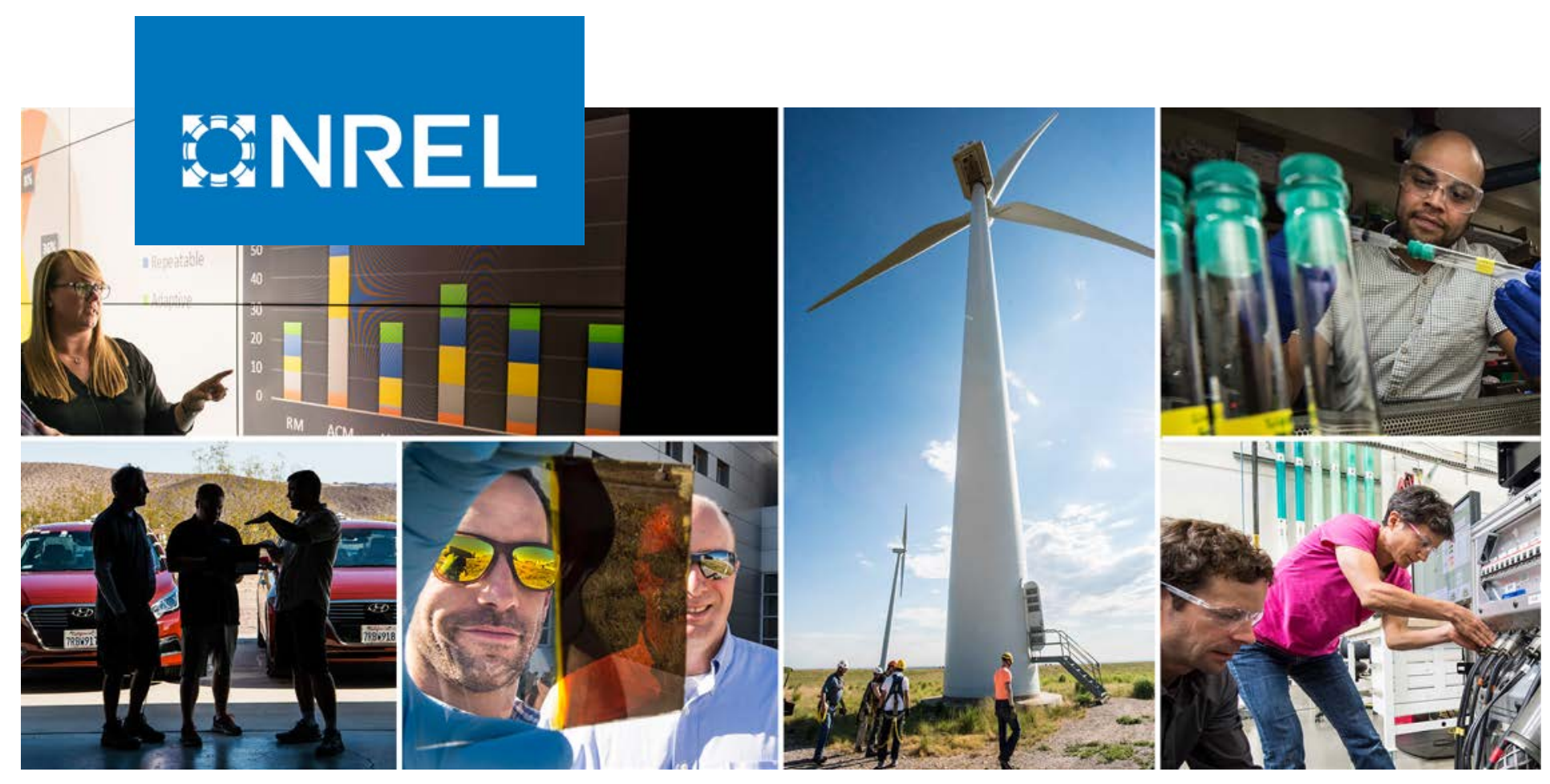

\title{
Workplace Charging Data Collection and Behavior
}

Christopher Neuman, Andrew Meintz, and Myungsoo Jun

National Renewable Energy Laboratory

NREL is a national laboratory of the U.S. Department of Energy

Office of Energy Efficiency \& Renewable Energy

Operated by the Alliance for Sustainable Energy, LLC

This report is available at no cost from the National Renewable Energy Laboratory (NREL) at www.nrel.gov/publications.
Technical Report

NREL/TP-5400-77515

November 2021 


\section{FNREL}

\section{Workplace Charging Data Collection and Behavior}

Christopher Neuman, Andrew Meintz, and Myungsoo Jun

National Renewable Energy Laboratory

\section{Suggested Citation}

Neuman, Christopher, Andrew Meintz, and Myungsoo Jun. 2021. Workplace Charging

Data Collection and Behavior. Golden, CO: National Renewable Energy Laboratory.

NREL/TP-5400-77515 https://www.nrel.gov/docs/fy22osti/77515.pdf.

NREL is a national laboratory of the U.S. Department of Energy Office of Energy Efficiency \& Renewable Energy Operated by the Alliance for Sustainable Energy, LLC

This report is available at no cost from the National Renewable Energy Laboratory (NREL) at www.nrel.gov/publications.

Contract No. DE-AC36-08GO28308
Technical Report

NREL/TP-5400-77515

November 2021

National Renewable Energy Laboratory 15013 Denver West Parkway Golden, CO 80401

303-275-3000 • www.nrel.gov 


\section{NOTICE}

This work was authored by the National Renewable Energy Laboratory, operated by Alliance for Sustainable Energy, LLC, for the U.S. Department of Energy (DOE) under Contract No. DE-AC36-08GO28308. Funding provided by the U.S. Department of Energy Office of Energy Efficiency and Renewable Energy Vehicle Technologies Office. The views expressed herein do not necessarily represent the views of the DOE or the U.S. Government.

This report is available at no cost from the National Renewable Energy Laboratory (NREL) at www.nrel.gov/publications.

U.S. Department of Energy (DOE) reports produced after 1991 and a growing number of pre-1991 documents are available free via www.OSTI.gov.

Cover Photos by Dennis Schroeder: (clockwise, left to right) NREL 51934, NREL 45897, NREL 42160, NREL 45891, NREL 48097, NREL 46526.

NREL prints on paper that contains recycled content. 


\section{Acknowledgments}

This study was supported by the U.S. Department of Energy's Vehicle Technologies Office. Thanks to the National Renewable Energy Laboratory's facilities team of Steve Frank and Lissa Myers for the hardware and data transfer support; to PowerFlex for establishing and cooperating with the electric vehicle supply equipment data transfer application programming interface (API); and to Michael Deneen for providing timely and thorough reviews. 


\section{List of Acronyms}

API

EVSE

MST

NREL

PEV application programming interface electric vehicle supply equipment

Mountain Standard Time

National Renewable Energy Laboratory

plug-in electric vehicle 


\section{Executive Summary}

This paper is a companion paper to the actual data being released. The data gathered and maintained by the National Renewable Energy Laboratory tracked nearly 400 vehicles during the course of a 56-month period and how they behave in a workplace charging capacity. The data show various dimensions of workplace charging, including arrival and departure times and differentiating between being plugged in and actively charging. The data are further enriched by examining the effect of free versus paid charging. There is also a distinction in data marked by the onset of the COVID-19 pandemic. From the beginning of the pandemic to the release of this report, employee usage has been reduced due to a remote work state at the laboratory. Pandemic influences have been called out because the smaller number of users tends to bias the distributions. Vehicles are owned and operated by employees and range from smaller-pack plugin hybrid electric vehicles to larger-pack battery electric vehicles. All personal identifiable information has been removed through a user anonymization process. 


\section{Table of Contents}

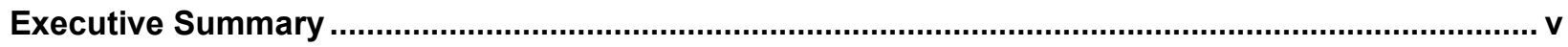

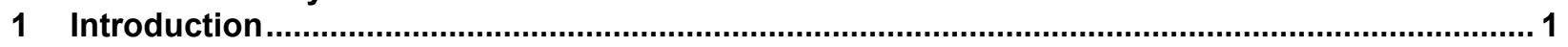

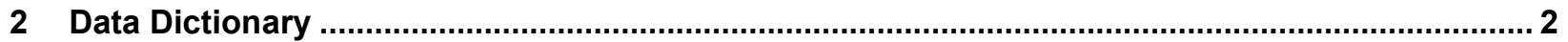

3 Methodology

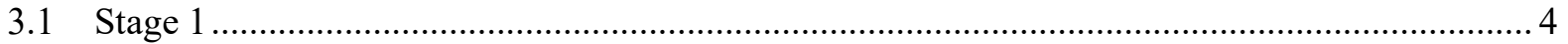

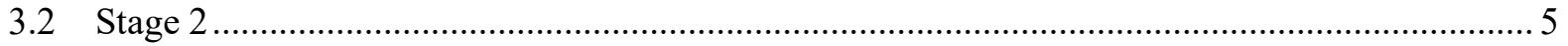

4 Results

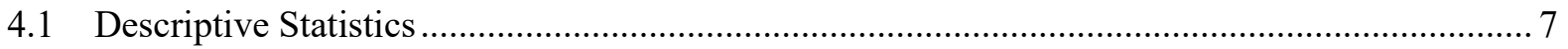

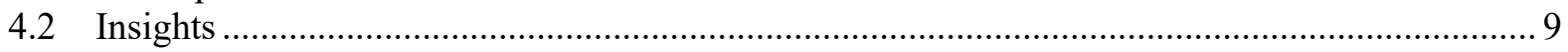

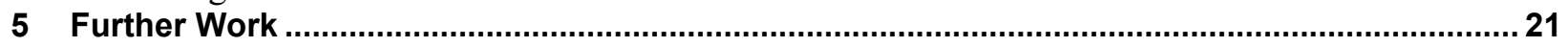

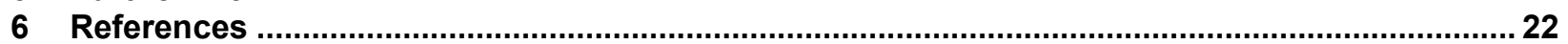




\section{List of Figures}

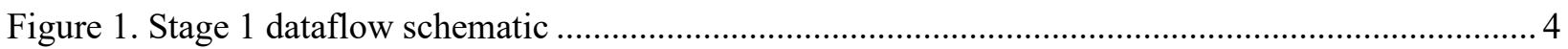

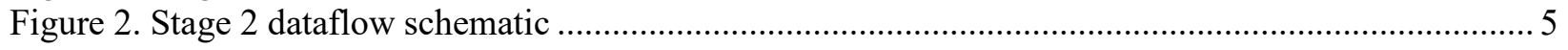

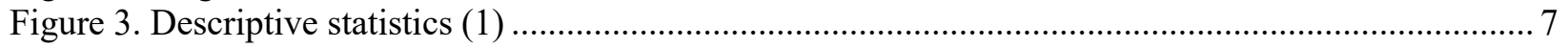

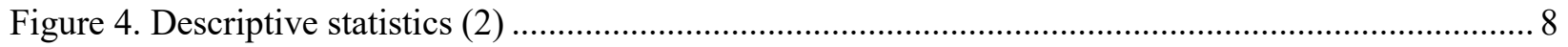

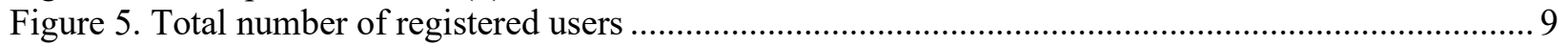

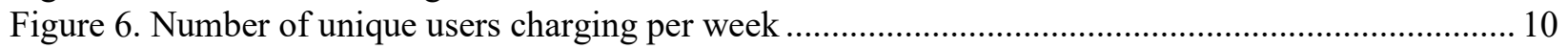

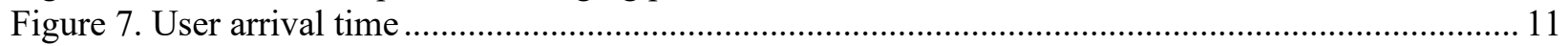

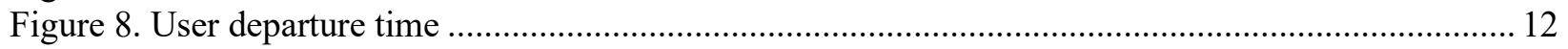

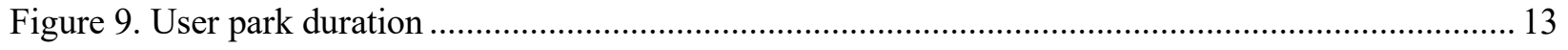

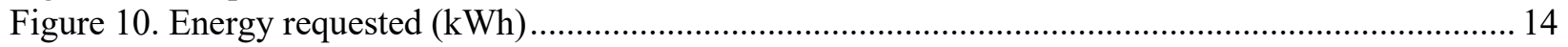

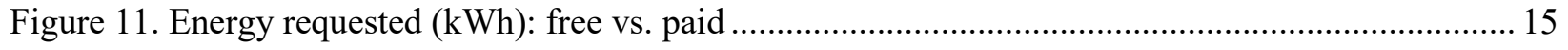

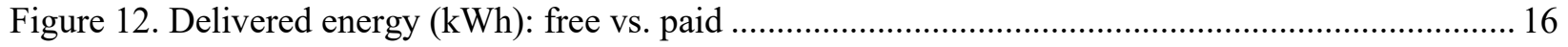

Figure 13. Difference between requested energy and energy delivered ................................................ 17

Figure 14. Average number of unique user plug-ins per day ................................................................. 18

Figure 15. Average intraday power profile of all EVSE combined, pre-COVID-19 .............................. 19

Figure 16. Average intraday power profile of all EVSE combined: COVID-19-influenced...................... 20 


\section{Introduction}

This data set has been created as part of larger U.S. Department of Energy-funded project: Smart Electric Vehicle Charging for a Reliable and Resilient Grid (RECHARGE). The National Renewable Energy Laboratory (NREL) in Golden, Colorado, has two sites where employees can charge their vehicles: a parking garage at the South Table Mountain campus with 96 Level 2 plug-in electric vehicle (PEV) chargers and the National Wind Technology Center with 16 Level 2 PEV chargers. Users may park at electric vehicle supply equipment (EVSE) station spots; once at these spots, they utilize a mobile app to request charging for their vehicle. All employees could charge their vehicle for free for about the first 2.5 years of EVSE operation. After this period, starting in May 2019, employees were required to pay for charging. The data were gathered in two different stages: before (Stage 1) and after (Stage 2) the PowerFlex installation. Details of the stages and how they affected collection are provided in Section 3: Methodology. 


\section{Data Dictionary}

This section details the names of the attributes within the gathered data, data type, definition of what each represents, and whether it is a derived input or a user input:

driverId - A nonsequential unique identifier integer data type for each registered user. This identifier is used so that no personal identifiable information is accessible for researchers utilizing this data set [derived input].

vehicle_model - A string that identifies the make and model of the vehicle being charged in each record. One driverId can have many "vehicle_model"s . Not every vehicle model is known because this input was not carried over from Stage 1 to Stage 2. Drivers with known vehicles were matched from Stage 1 to Stage 2, although vehicles registered after Stage 1 have no known established model [user input].

request_entry_time - A time stamp data type with a Mountain Standard Time (MST) time zone; this is the date and time when the request for vehicle charging was placed from a mobile device [derived input].

expected_departure - A time stamp data type with MST time zone; this is the date and time when the driver expects to depart. In Stage 1, this was based on a 5-minute resolution departure selection, whereas Stage 2 requests a duration of park time [user input].

Station - A unique string data type that denotes the EVSE station and port; it can also be used as a surrogate for parking space. There are two conventions for the texts denoting the two charge sites, one using a two-digit number concatenated with a letter and the other using a six-character alphanumeric name separated by a hyphen to denote space [user input].

start_date_time - A time stamp data type with MST time zone; this is the date and time when the EVSE was connected to the vehicle [derived input].

end_date_time - A time stamp data type with MST time zone; this is the date and time when the EVSE was disconnected from the vehicle [derived input].

start_charge - A time stamp data type with MST time zone; this is the date and time when power started to flow to the vehicle [derived input].

termin_charge - A time stamp data type with MST time zone; this is the date and time when power to the vehicle terminated [derived input].

controlled_duration - This float data type shows the amount of time in hours that the vehicle charging was controlled or throttled. Charge control was implemented during Stage 1 in some cases; this is used to identify those cases [derived input].

miles_requested - This integer data type is the number of miles requested by the user through the app [user input]. 
max_charge_power - The maximum charge power during the charge session, this can be used to determine the charge level of the session between 3.3 and $6.6 \mathrm{~kW}$ [derived input].

kwh_requested - The $\mathrm{kWh}$ requested from the charge session as a function of the miles requested and useable high-voltage pack capacity [derived input].

energy_charged - This float data type is the amount of kWh that were actually delivered to the vehicle during the charge session [derived input].

cost_for_session - The cost of the charge session as a result of the user flexibility (park time duration) and energy demand. There is a cost attached to records when charging was free; this is a theoretical cost of what would have been charged based on the previous metrics [derived input].

afterPaid - Boolean data type signifying whether the record was before or after payment was required for charging [derived input]. 


\section{Methodology}

\subsection{Stage 1}

Stage 1, which is also synonymous with the free stage, lasted from November 2016 to May 2019. In this stage, the data were gathered and charging was managed according to the diagram in Figure 1. Vehicles would plug into the EVSE in the garage, and the status of the EVSE was reported as A (available), B (connected but not charging) or $\mathrm{C}$ (charging). There was also the ability to set an EVSE set point, which relates to the controlled duration field. Typically, the charging management server would allow the vehicle to charge at the full defaulted rate $(3.3 \mathrm{~kW}$ of $6.6 \mathrm{~kW}$ ). All driver inputs were uploaded to a cloud server; these user inputs are defined in the data dictionary in Section 2 as "[user input]." In Stage 1, the data were housed within the charging management server and calculations would be aided by the EVSE status information. Together, the EVSE meter and garage EVSE would determine all power delivery data. Given that the driver data and power data were stored separately, these data needed to be joined by user and time to generate the final Stage 1 full data set. Also, given the disposition of the data set, Stage 1 was not able to supply information regarding when the vehicles actually transitioned from status $\mathrm{B}$ to $\mathrm{C}$ in many cases.

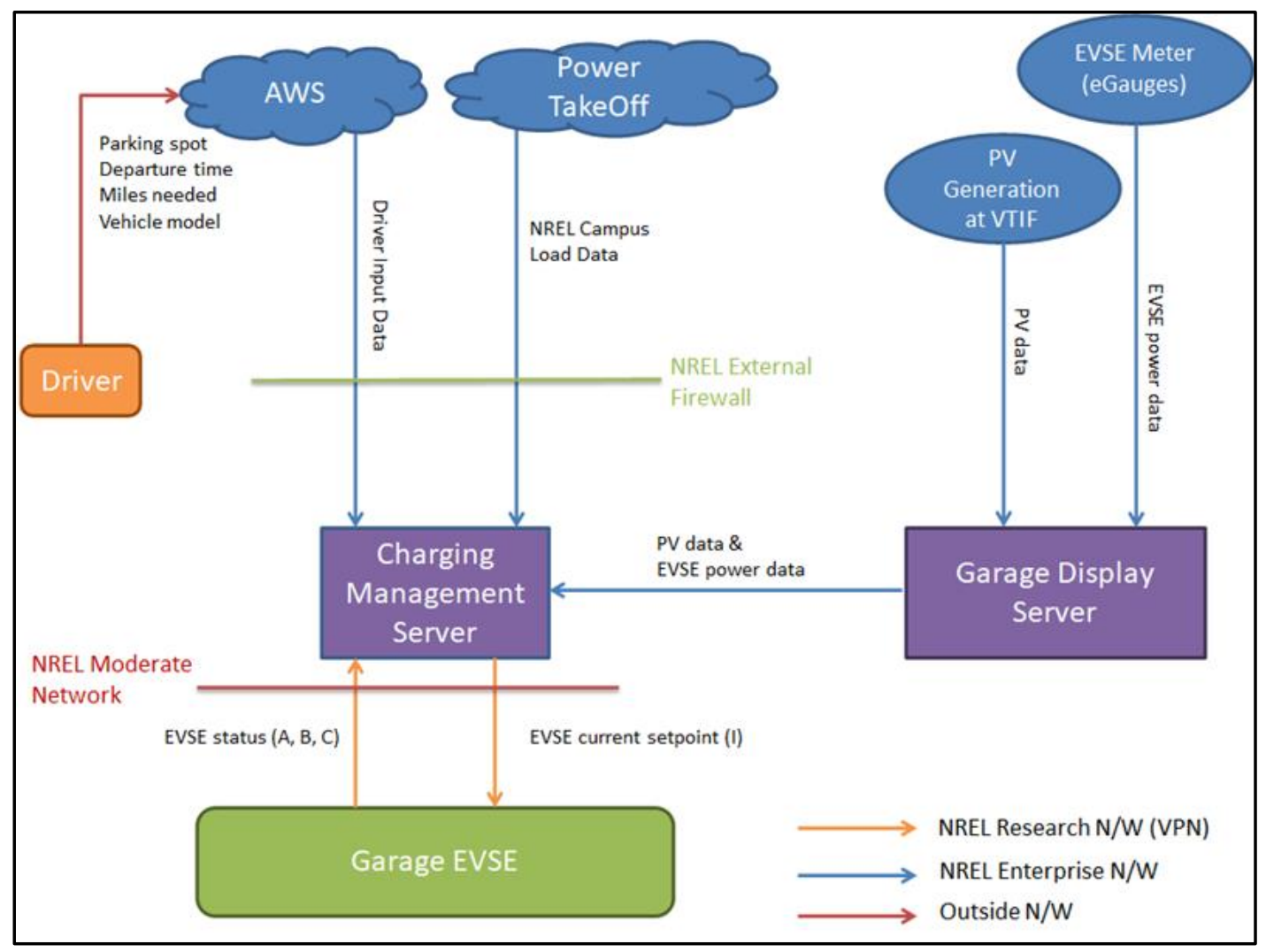

Figure 1. Stage 1 dataflow schematic 


\subsection{Stage 2}

Stage 2 started June 2019 and runs to the current date of publishing; this stage is the paid stage of the data gathering work. Figure 2 gives a general flow of the data gathering operation. EVSE data are generated in a time series fashion and then used for aggregation purposes at PowerFlex; the data are available to NREL through the PowerFlex application programming interface (API). The session data, which is information on the user's session not having to do with the power flow, are also available. Finally, the time series data are used in raw form to determine charge rate and when the vehicle finished charging but was not yet unplugged, as well as the vehicle's maximum charge rate. All the previously mentioned information is then put together at NREL, merging Stage 1 and Stage 2 data and adding enhancements that are calculated fields that may be interesting for researchers, such as afterPaid. Given that the time series data are purged on a 45day moving window, the data are updated on a monthly basis to ensure that no information is lost.

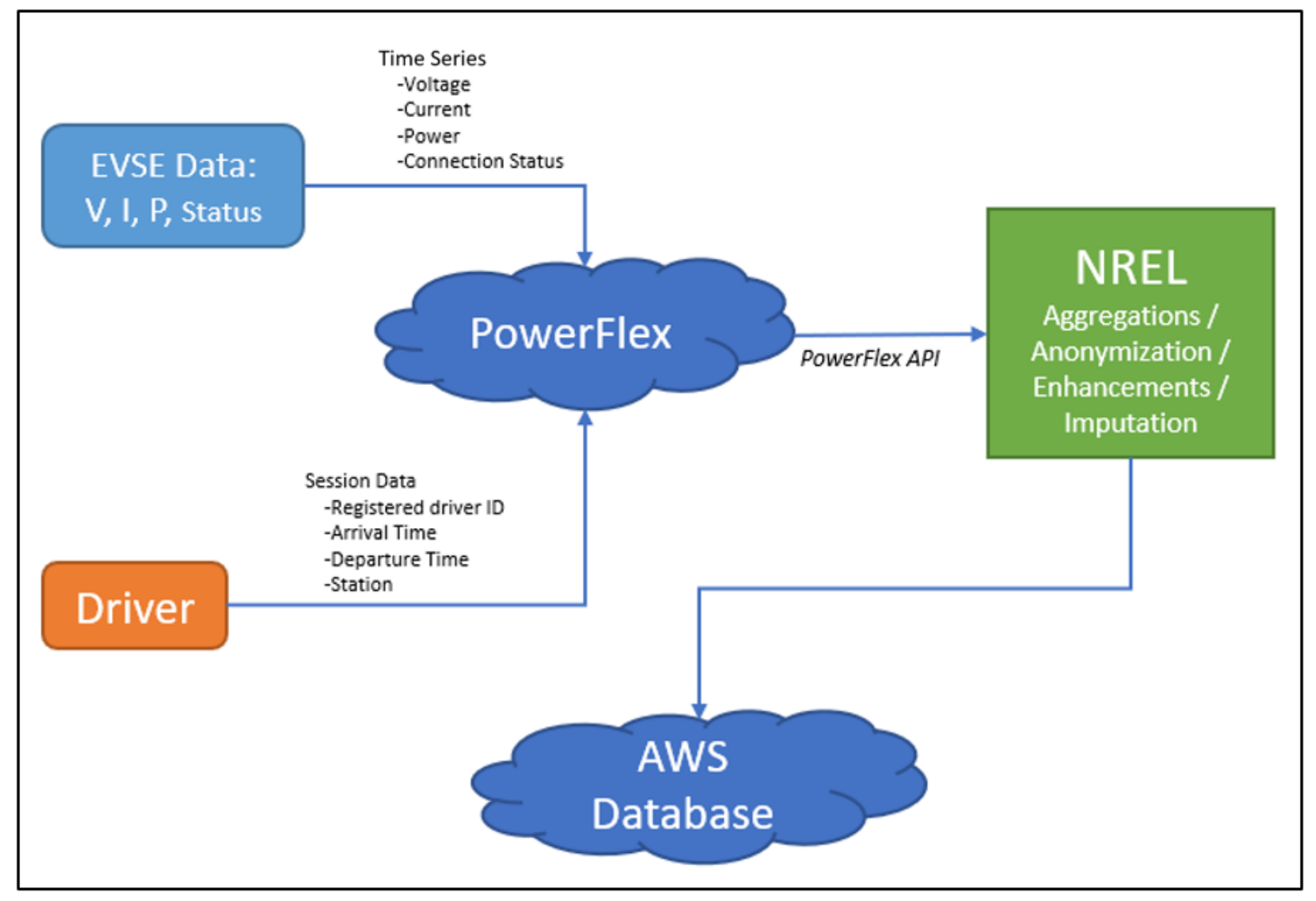

Figure 2. Stage 2 dataflow schematic 


\section{Results}

The results have been separated into descriptive statistics and insights; the descriptive statistics are available in Figures 3 and 4, and the remaining figures help describe the initial data insights. Insights have been broken up by paid vs. free and "pre-COVID-19" vs. "COVID-influenced" given that combining all of the data without this distinction would bias key takeaways. 


\subsection{Descriptive Statistics}

Dimensions: $39303 \times 15$

Duplicates: 6

\begin{tabular}{|c|c|c|c|c|}
\hline Variable & Stats / Values & Freqs ( $\%$ of Valid) & Graph & Missing \\
\hline $\begin{array}{l}\text { driverld } \\
\text { [factor] }\end{array}$ & $\begin{array}{l}1.2574 \\
2.2694 \\
3.2692 \\
4.27 \\
5.2570 \\
6.2582 \\
7.402 \\
8.2616 \\
9.2635 \\
10.99 \\
\text { [ } 375 \text { others ] }\end{array}$ & $\begin{array}{r}1207(3.1 \%) \\
822(2.1 \%) \\
780(2.0 \%) \\
701(1.8 \%) \\
653(1.7 \%) \\
606(1.5 \%) \\
559(1.4 \%) \\
584(1.5 \%) \\
563(1.4 \%) \\
527(1.3 \%) \\
32301(82.2 \%)\end{array}$ & & $\begin{array}{c}0 \\
(0 \%)\end{array}$ \\
\hline $\begin{array}{l}\text { vehicle_model } \\
\text { [factor] }\end{array}$ & $\begin{array}{l}\text { 1. Nissan LEAF } \\
\text { 2. Chevy Volt } \\
\text { 3. BMW i3 } \\
\text { 4. Chevy Bolt } \\
\text { 5. Tesla Model } 3 \\
\text { 6. Prius Prime } \\
\text { 7. Ford Fusion } \\
\text { 8. Audi A3 E-Tron } \\
\text { 9. Chevy Spark } \\
\text { 10. Honda Clarity } \\
\text { [ } 16 \text { others ] }\end{array}$ & $\begin{array}{r}13576(41.9 \%) \\
9911(30.6 \%) \\
1453(4.5 \%) \\
1316(4.1 \%) \\
1051(3.2 \%) \\
857(2.6 \%) \\
649(2.0 \%) \\
655(2.0 \%) \\
553(1.7 \%) \\
501(1.5 \%) \\
1856(5.7 \%)\end{array}$ & $\begin{array}{l}\frac{\square}{\square} \\
\square \\
\square \\
\square \\
\square \\
0 \\
0\end{array}$ & $\begin{array}{c}6925 \\
(17.62 \%)\end{array}$ \\
\hline $\begin{array}{l}\text { request_entry_time } \\
\text { [POSIXct, POSIXt] }\end{array}$ & $\begin{array}{l}\min : 2016-11-0311: 06: 13 \\
\text { med : 2018-11-28 11:04:12 } \\
\max : 2021-07-1111: 50: 00 \\
\text { range : } 4 y \text { 8m 8d 0H 43M 47S }\end{array}$ & 39090 distinct values & & $\begin{array}{c}0 \\
(0 \%)\end{array}$ \\
\hline $\begin{array}{l}\text { station } \\
\text { [factor] }\end{array}$ & $\begin{array}{l}1.01 \mathrm{~B} \\
2.08 \mathrm{~B} \\
3.08 \mathrm{~A} \\
4.06 \mathrm{~A} \\
5.07 \mathrm{~A} \\
6.02 \mathrm{~B} \\
7.07 \mathrm{~B} \\
8.03 \mathrm{~B} \\
9.02 \mathrm{~A} \\
10.04 \mathrm{~A} \\
{[131 \text { others ] }}\end{array}$ & $\begin{array}{r}1180(3.0 \%) \\
1021(2.6 \%) \\
1003(2.6 \%) \\
949(2.4 \%) \\
928(2.4 \%) \\
938(2.4 \%) \\
920(2.3 \%) \\
898(2.3 \%) \\
891(2.3 \%) \\
890(2.3 \%) \\
29685(75.5 \%)\end{array}$ & & $\begin{array}{c}0 \\
(0 \%)\end{array}$ \\
\hline
\end{tabular}

Figure 3. Descriptive statistics (1) 


\begin{tabular}{|c|c|c|c|c|}
\hline $\begin{array}{l}\text { start_date_time } \\
\text { [POSIXct, POSIXt] }\end{array}$ & $\begin{array}{l}\min : 2019-04-0106: 34: 14 \\
\operatorname{med}: 2019-12-0309: 05: 12 \\
\max : 2021-07-1111: 50: 29 \\
\text { range : } 2 y 3 \mathrm{~m} \mathrm{10d} \mathrm{5H} \mathrm{16M} \mathrm{15S}\end{array}$ & 13292 distinct values & & $\begin{array}{c}25898 \\
(65.89 \%)\end{array}$ \\
\hline $\begin{array}{l}\text { end_date_time } \\
\text { [POSIXct, POSIXt] }\end{array}$ & $\begin{array}{l}\min : 2019-04-0106: 58: 11 \\
\operatorname{med}: 2019-12-0316: 40: 27 \\
\max : 2021-07-1117: 19: 57 \\
\text { range : } 2 y 3 \mathrm{~m} 10 \mathrm{~d} 10 \mathrm{H} 21 \mathrm{M} 46 \mathrm{~S}\end{array}$ & 13386 distinct values & मा & $\begin{array}{c}25898 \\
(65.89 \%)\end{array}$ \\
\hline $\begin{array}{l}\text { start_charge } \\
\text { [POSIXct, POSIXt] }\end{array}$ & $\begin{array}{l}\min : 2016-11-0310: 45: 00 \\
\operatorname{med}: 2018-10-0411: 11: 00 \\
\max : 2021-07-1111: 50: 45 \\
\text { range : } 4 y \text { 8m } 8 d 1 \mathrm{H} 5 \mathrm{M} 45 \mathrm{~S}\end{array}$ & 27545 distinct values & & $\begin{array}{c}3669 \\
(9.34 \%)\end{array}$ \\
\hline $\begin{array}{l}\text { termin_charge } \\
\text { [POSIXct, POSIXt] }\end{array}$ & $\begin{array}{l}\min : 2016-11-0311: 00: 00 \\
\operatorname{med}: 2018-10-0412: 32: 00 \\
\max : 2021-07-1114: 55: 06 \\
\text { range : } 4 \mathrm{y} 8 \mathrm{~m} 8 \mathrm{~d} 3 \mathrm{H} 55 \mathrm{M} 6 \mathrm{~S}\end{array}$ & 29296 distinct values & & $\begin{array}{c}3669 \\
(9.34 \%)\end{array}$ \\
\hline $\begin{array}{l}\text { controlled_duration } \\
\text { [numeric] }\end{array}$ & $\begin{array}{l}\text { Mean }(\mathrm{sd}): 0.2(0.7) \\
\min <\operatorname{med}<\max : \\
0<0<8.1 \\
I Q R(C V): 0(4.1)\end{array}$ & 206 distinct values & & $\begin{array}{c}34567 \\
(87.95 \%)\end{array}$ \\
\hline $\begin{array}{l}\text { miles_requested } \\
\text { [numeric] }\end{array}$ & $\begin{array}{l}\text { Mean }(\mathrm{sd}): 49.6(33.2) \\
\min <\operatorname{med}<\max : \\
1<40<285 \\
I Q R(\mathrm{CV}): 30(0.7)\end{array}$ & 186 distinct values & & $\begin{array}{c}0 \\
(0 \%)\end{array}$ \\
\hline $\begin{array}{l}\text { max_charge_power } \\
\text { [numeric] }\end{array}$ & $\begin{array}{l}\text { Mean }(\mathrm{sd}): 4(1.8) \\
\min <\operatorname{med}<\max : \\
0<3.3<7.5 \\
I Q R(\mathrm{CV}): 3.2(0.5)\end{array}$ & 25852 distinct values & & $\begin{array}{c}3669 \\
(9.34 \%)\end{array}$ \\
\hline $\begin{array}{l}\text { kwh_requested } \\
\text { [numeric] }\end{array}$ & $\begin{array}{l}\text { Mean }(\mathrm{sd}): 15.9(10) \\
\min <\operatorname{med}<\max : \\
0.4<14<99.8 \\
I Q R(\mathrm{CV}): 10.5(0.6)\end{array}$ & 790 distinct values & & $\begin{array}{c}0 \\
(0 \%)\end{array}$ \\
\hline $\begin{array}{l}\text { energy_charged } \\
\text { [numeric] }\end{array}$ & $\begin{array}{l}\text { Mean }(\mathrm{sd}): 11.1(7.7) \\
\min <\operatorname{med}<\max \\
0<9.5<68.3 \\
\text { IQR }(\mathrm{CV}): 7.8(0.7)\end{array}$ & 35543 distinct values & & $\begin{array}{c}0 \\
(0 \%)\end{array}$ \\
\hline $\begin{array}{l}\text { cost_for_session } \\
\text { [numeric] }\end{array}$ & $\begin{array}{l}\text { Mean }(\mathrm{sd}): 1.2(0.8) \\
\min <\operatorname{med}<\max : \\
0<1<9.8 \\
I Q R(\mathrm{CV}): 0.8(0.7)\end{array}$ & 36079 distinct values & & $\begin{array}{c}0 \\
(0 \%)\end{array}$ \\
\hline $\begin{array}{l}\text { afterPaid } \\
\text { [logical] }\end{array}$ & $\begin{array}{l}\text { 1. FALSE } \\
\text { 2. TRUE }\end{array}$ & $\begin{array}{l}26254(66.8 \%) \\
13049(33.2 \%)\end{array}$ & & $\begin{array}{c}0 \\
(0 \%)\end{array}$ \\
\hline
\end{tabular}

Figure 4. Descriptive statistics (2)

This report is available at no cost from the National Renewable Energy Laboratory at www.nrel.gov/publications. 


\subsection{Insights}

Total Number of Registered Users

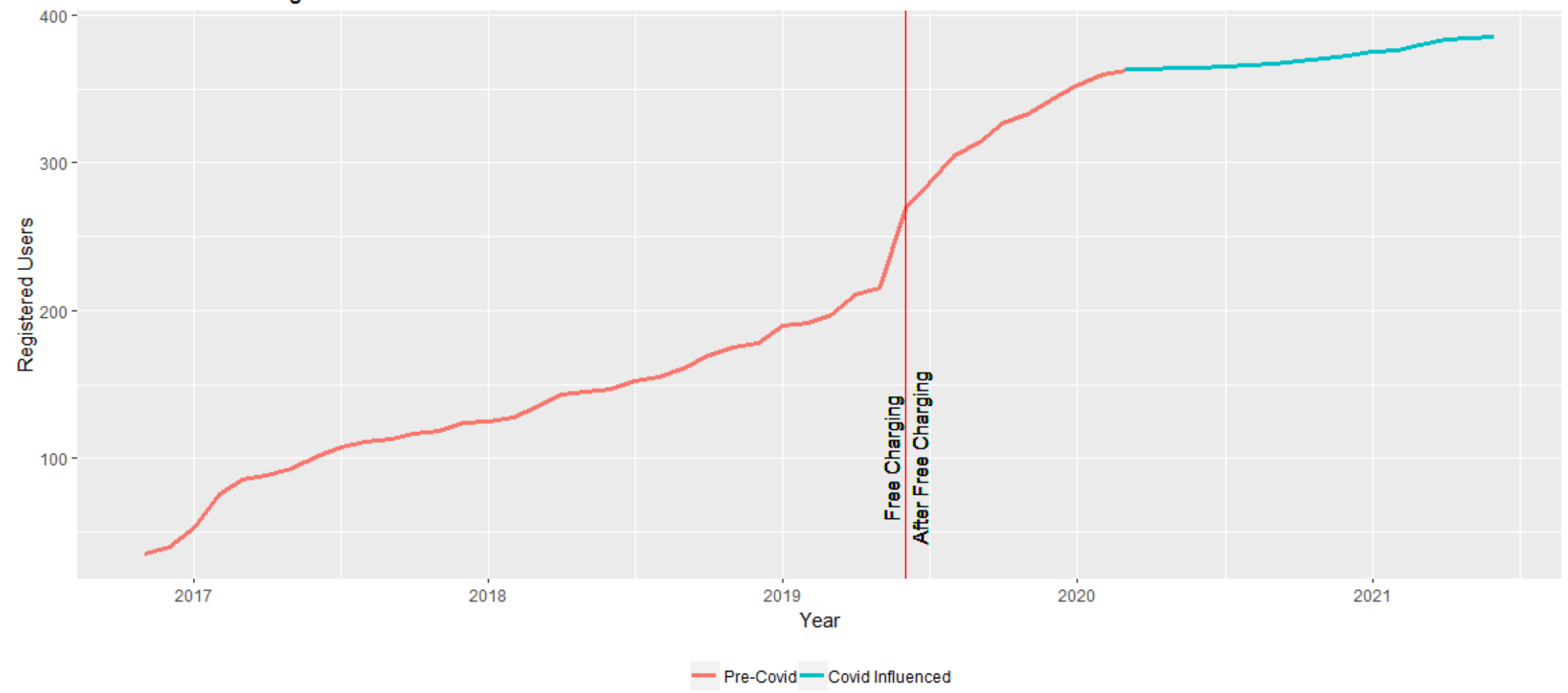

\section{Figure 5. Total number of registered users}

Figure 5 shows the cumulative number of registered users by year. This is the total number of users that have registered and includes those that stop utilizing the charging service. During the initial registration period there was a jump as all PEV users onboarded, after which there was a fairly linear rise in registrations. The slope increases as more people register for the service, and then the registration counts begin to slow when COVID-19 influences come into play. 


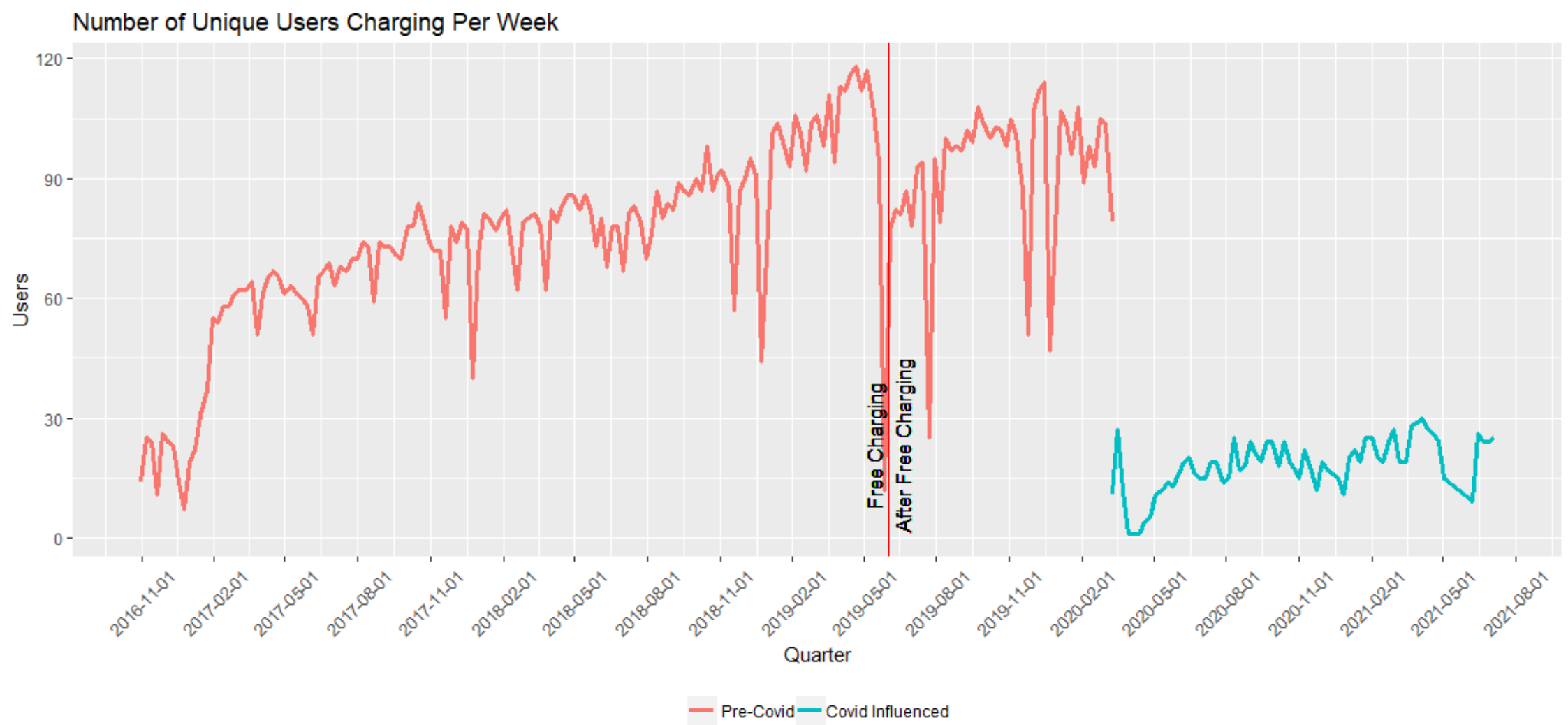

Figure 6. Number of unique users charging per week

Figure 6 shows the unique number of vehicles charging per week. This plot is a good estimate of the number of different people utilizing the charging stations, as looking at just the number of charges could be deceptive if a small number of vehicles accounted for a large percent of charges. There is a significant dip in users when the service ceased to be free, but this is misleading because the dip was caused by the installation of new EVSE to upgrade to the Stage 2 system. During this installation, vehicles often could not charge while system bugs were being resolved. In subsequent months the utilization comes back to nearly the same level as when the service was free, although it is difficult to tell whether these numbers would be higher without required payment. After increased work from home caused by the COVID-19 pandemic, we can see the number of users drop dramatically. For the remainder of the document, COVID-19 will be included when explanatorily relevant. 


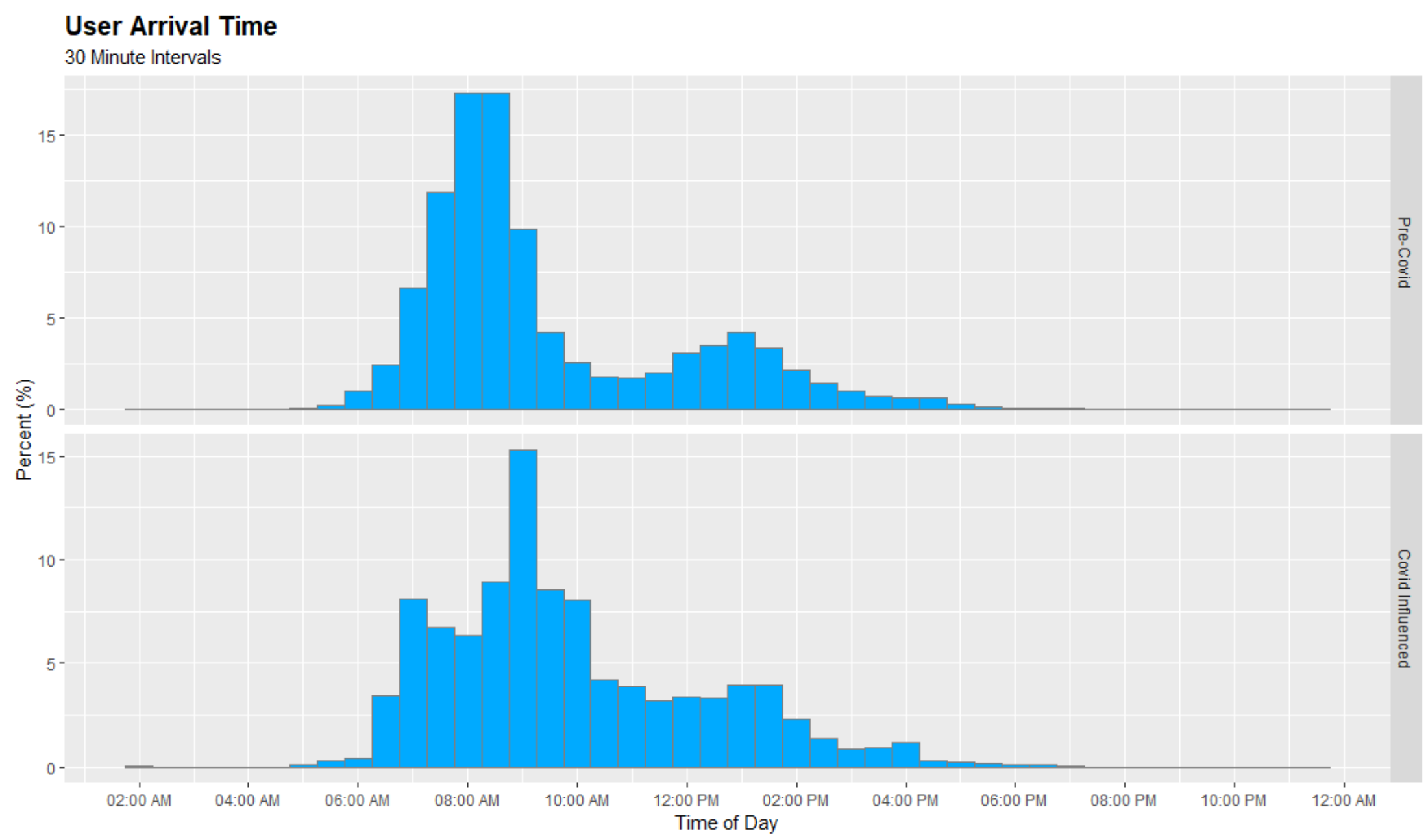

Figure 7. User arrival time

Figure 7 shows the user arrival time, which is when their vehicle arrives according to the time that a user entered their charge request. The largest number of people arrive in the morning from home and plug in upon arrival, tapering off near 10 a.m. Shortly afterward, the number of vehicles picks up in charging, which would include people returning from lunch or those that came to work too late for a spot moving into a vacated spot by those going to lunch. 


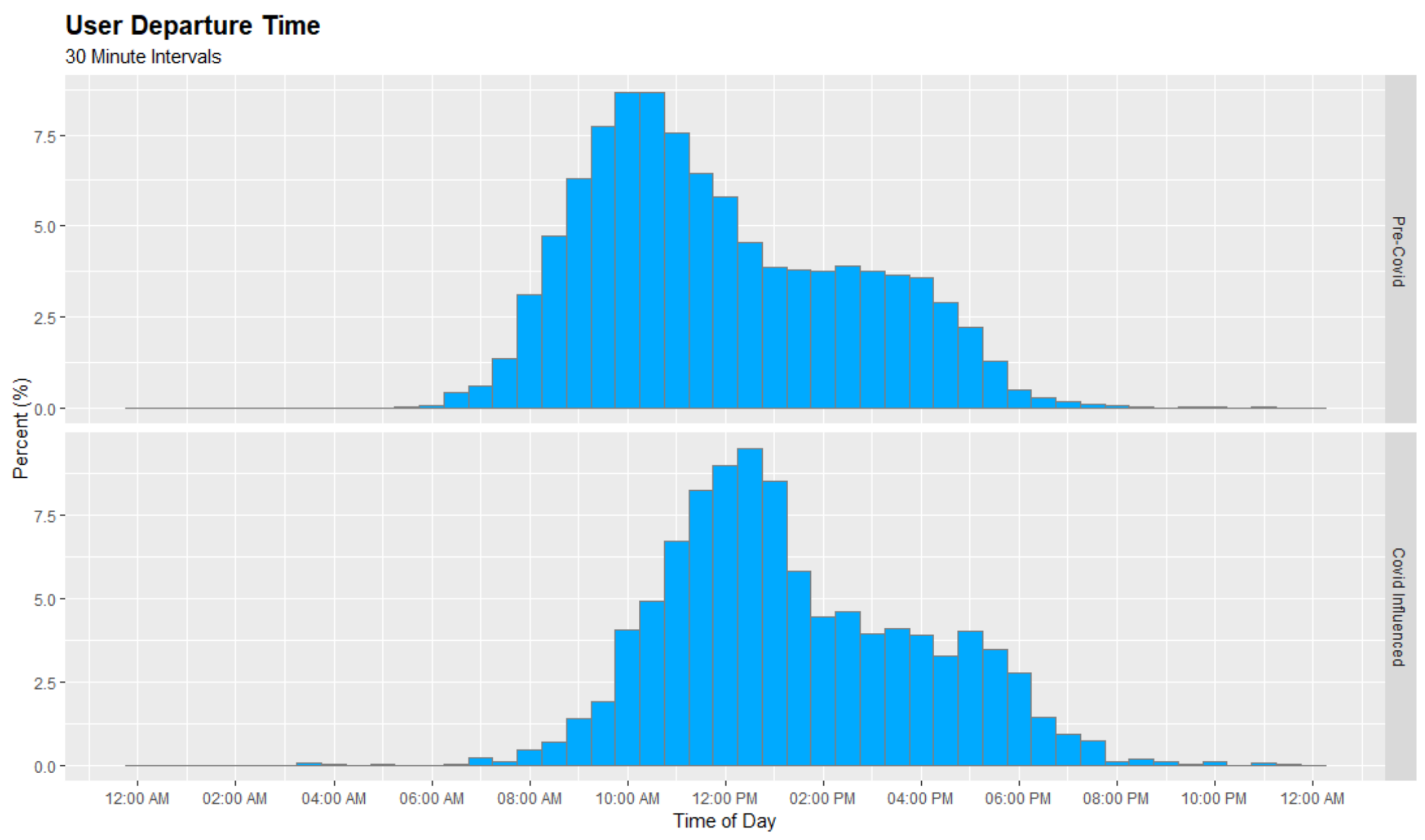

Figure 8. User departure time

Figure 8 shows when vehicles depart; as with arrivals, the pre-COVID-19 distributions are bimodal but much less pronounced. This is because unplugging/departure is based on leaving or just unplugging after receiving full charge. 


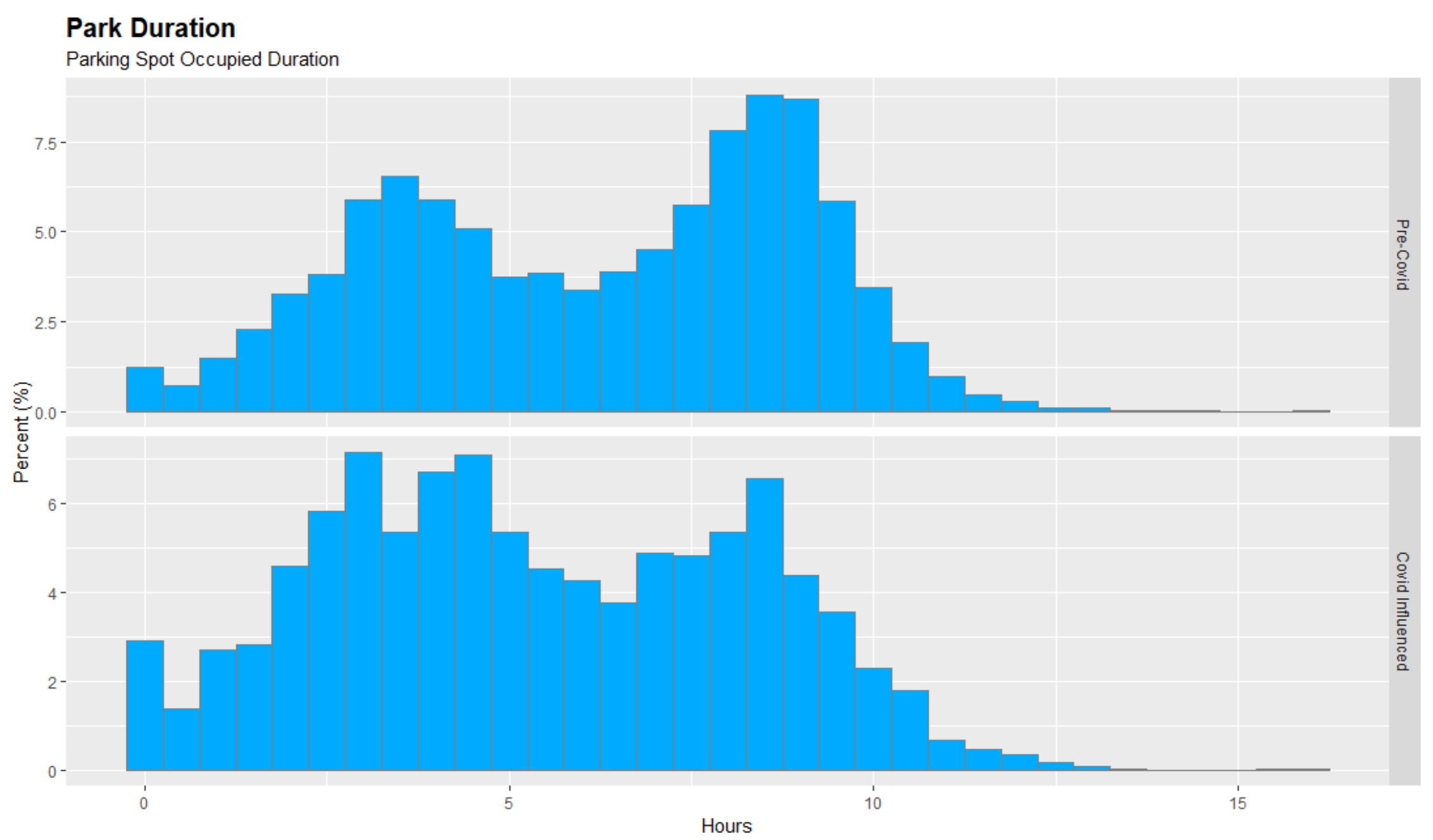

Figure 9. User park duration

Figure 9 is the user park duration, or the amount of time that a user remains parked at the station spot. The distribution is bimodal showing two types of users: those that park at a station until lunch and those that park from morning arrival to afternoon departure. 


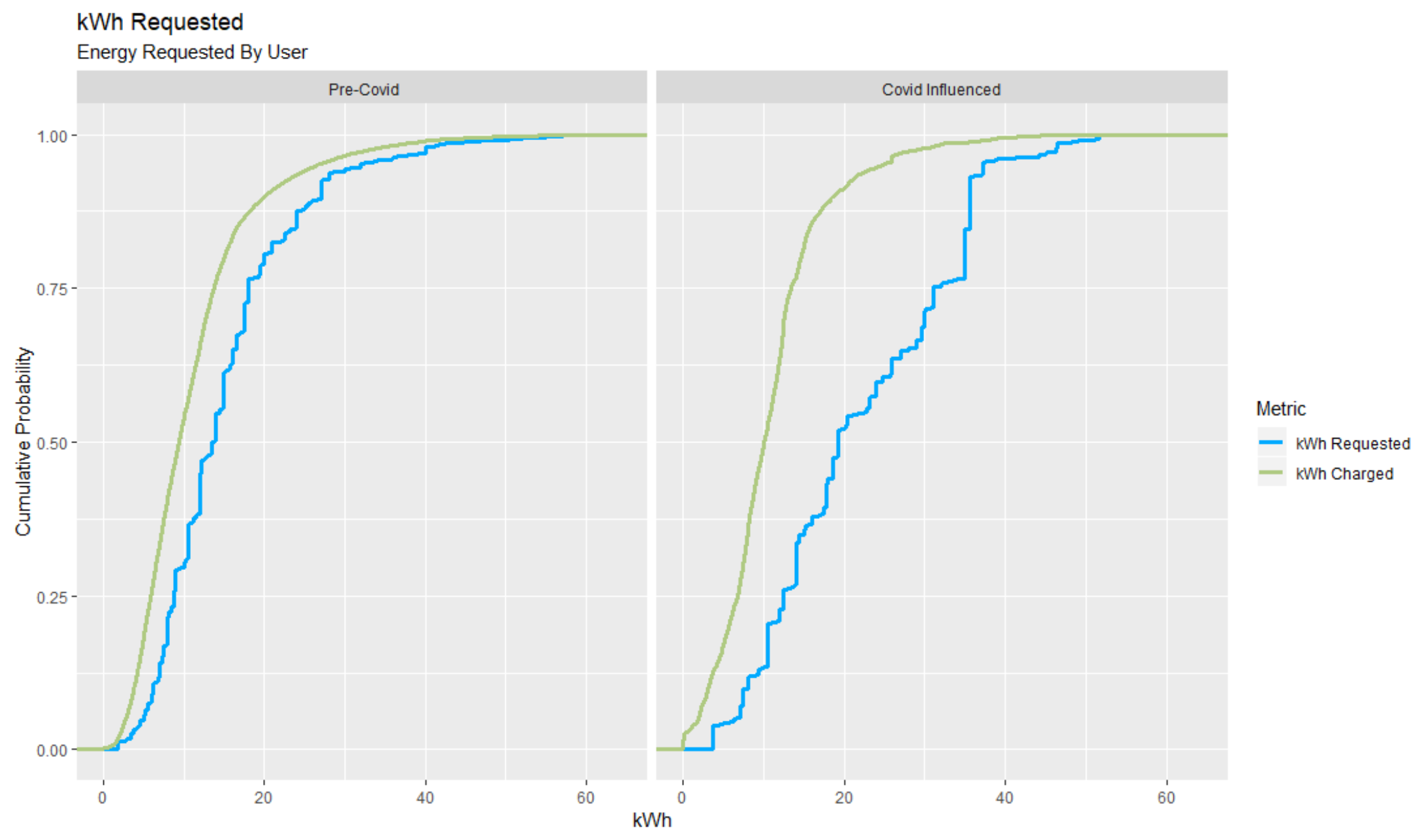

Figure 10. Energy requested (kWh)

Figure 10 is a cumulative distribution function showing the energy requested by the user via the app and the actual energy delivered. This plot includes both paid and free charging. The amount of energy requested is routinely higher than the amount delivered, meaning that users are requesting or estimating more energy than they need, or they need to terminate charging early on a regular basis. 


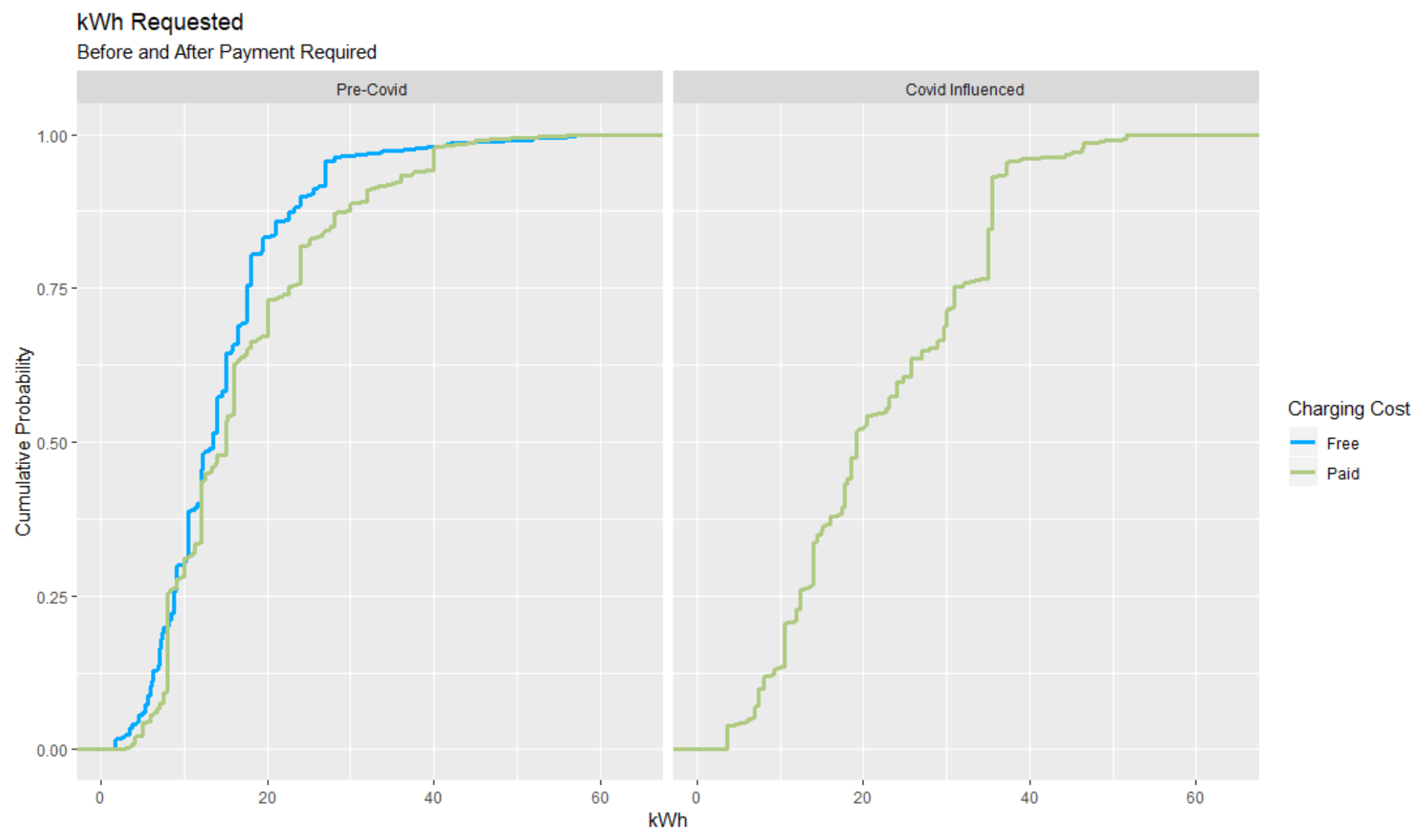

Figure 11. Energy requested (kWh): free vs. paid

Figure 11 displays how many kilowatt-hours users requested during free vs. paid scenarios. Users requested less energy per charge when the energy was free. There are two likely reasons for this. One is that when payment is required, those charging just because it is free and not out of necessity are weeded out. Another possibility is that the paid rate was instituted later than the free scenario, and more higher-capacity battery electric vehicles were registered later in the data gathering effort. 


\section{kWh Delivered}

Before and After Payment Required
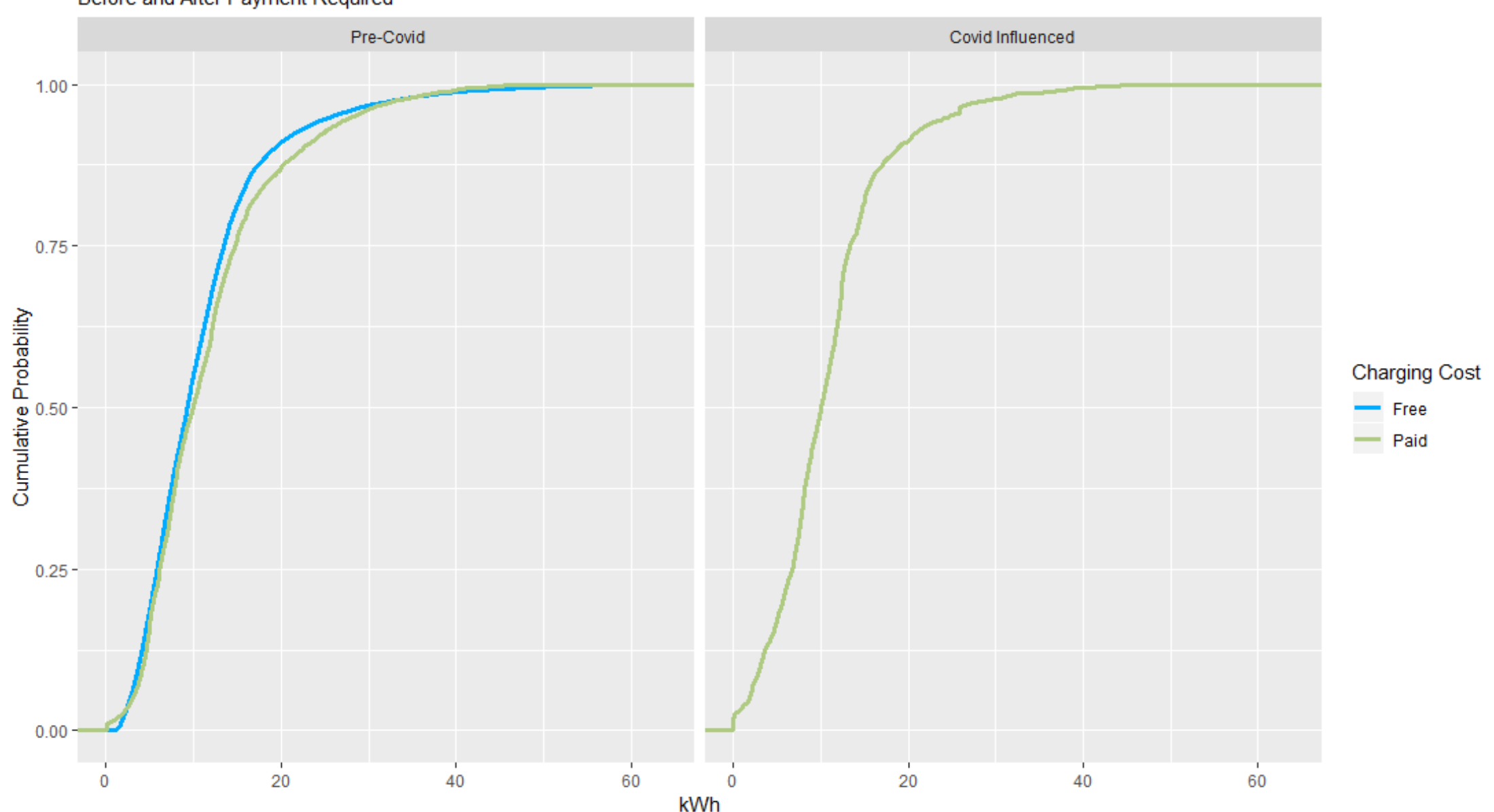

Figure 12. Delivered energy (kWh): free vs. paid

Figure 12 displays the kilowatt-hours delivered in a charge session, divided into free vs. paid. The EVSE delivered more energy per charge when the energy was not free. The most likely reason for this is that when payment is required, those charging just because it is free and not out of necessity are weeded out. This can be said with more certainty over Figure 11 given the left-hand side tail, which shows a low slope and a decrease in very small kilowatt-hours-delivered charge events for the paid time period. 


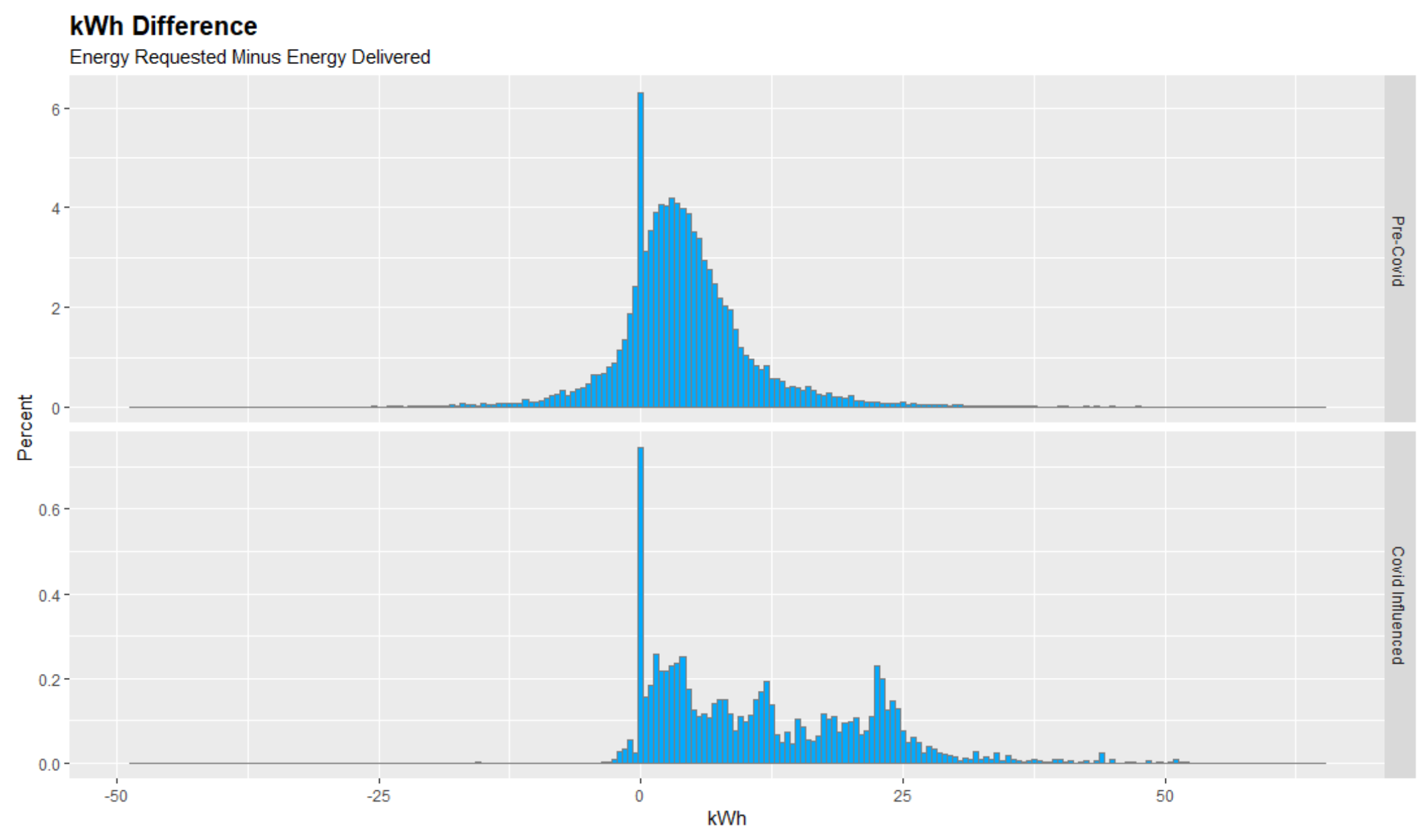

Figure 13. Difference between requested energy and energy delivered

Figure 13 shows the difference between the energy requested and the energy delivered. As called out in previous plots, users tend to overestimate their energy needs - approximately $4 \mathrm{kWh}$ on average. There is also an amount of people that underestimate their delivered energy, shown in the tail to the left of zero. It is also worth noting that there are people that charge exactly the amount requested, which is the peak (mode) of $0 \mathrm{kWh}$. 


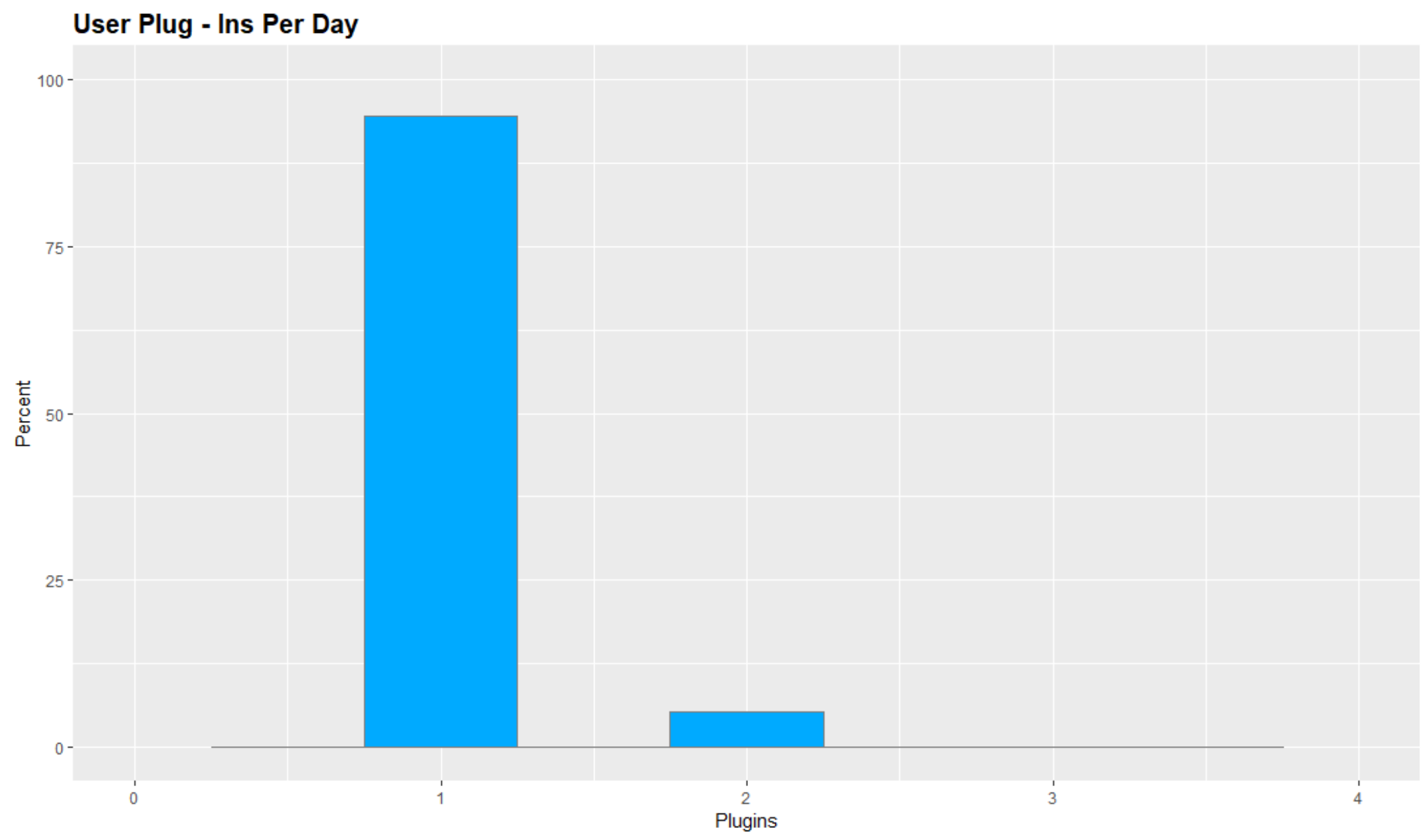

Figure 14. Average number of unique user plug-ins per day

Figure 14 shows the number of plug-ins per day, displayed as a percent plot of the number of plug-ins by an individual user on a given day. This shows that $>95 \%$ of users only plug in their vehicle once per day, with a smaller amount plugging in twice and very rare occurrences of three plug-in events. 


\section{Average Power Profile Pre-Covid}

kW \& Shape of User Charge Behaviour

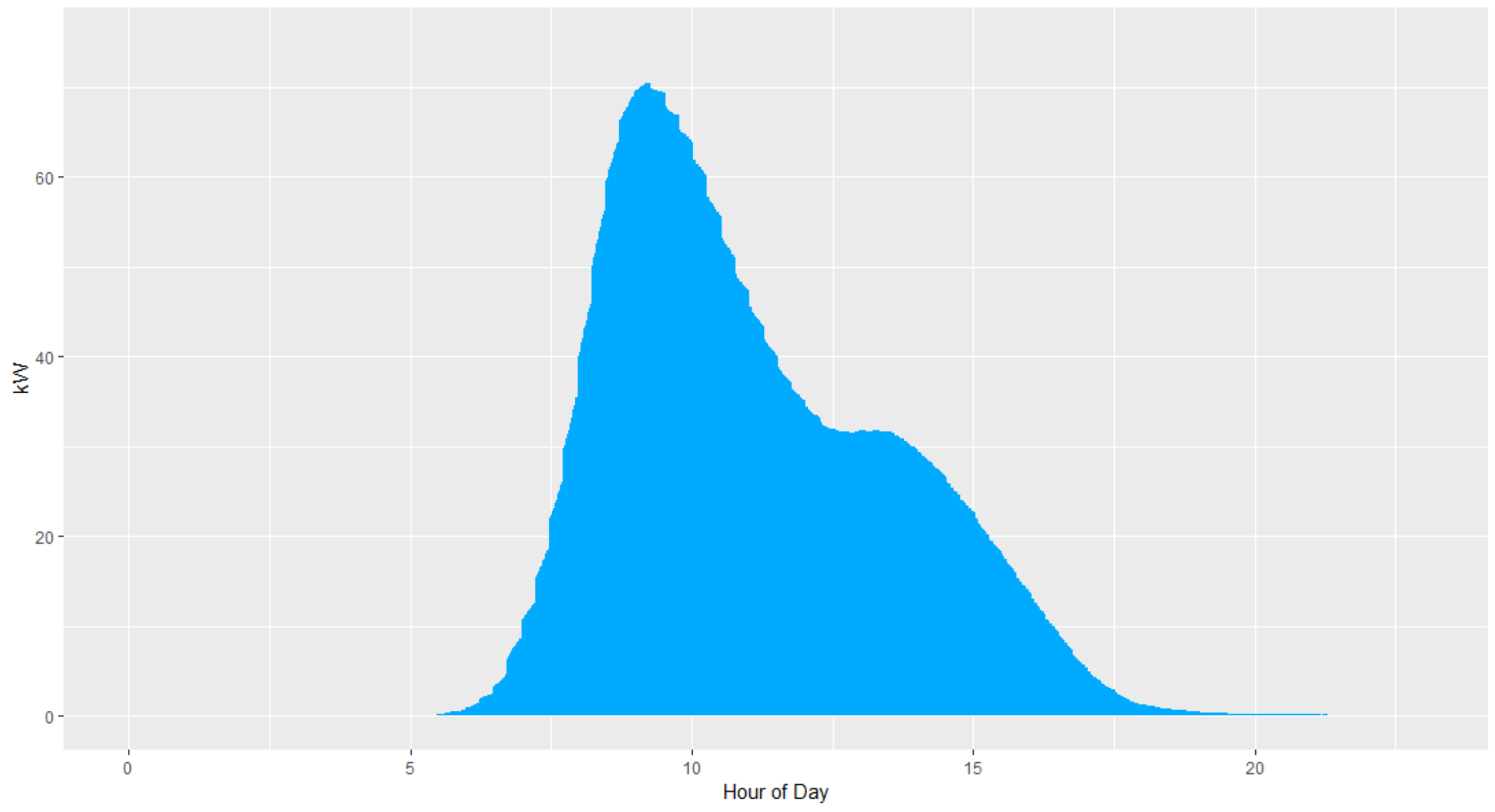

Figure 15. Average intraday power profile of all EVSE combined, pre-COVID-19

Figure 15 shows the average power consumed by all EVSE by hour of the day. The peak power is at 9 a.m., and on average is just above $75 \mathrm{~kW}$ of demand. This plot represents the overall shape of the power demand curve, but because every day before COVID-19 is included, the 9 a.m. peak would be higher over time as more users participate. 


\section{Average Power Profile Covid Influenced}

kW \& Shape of User Charge Behaviour

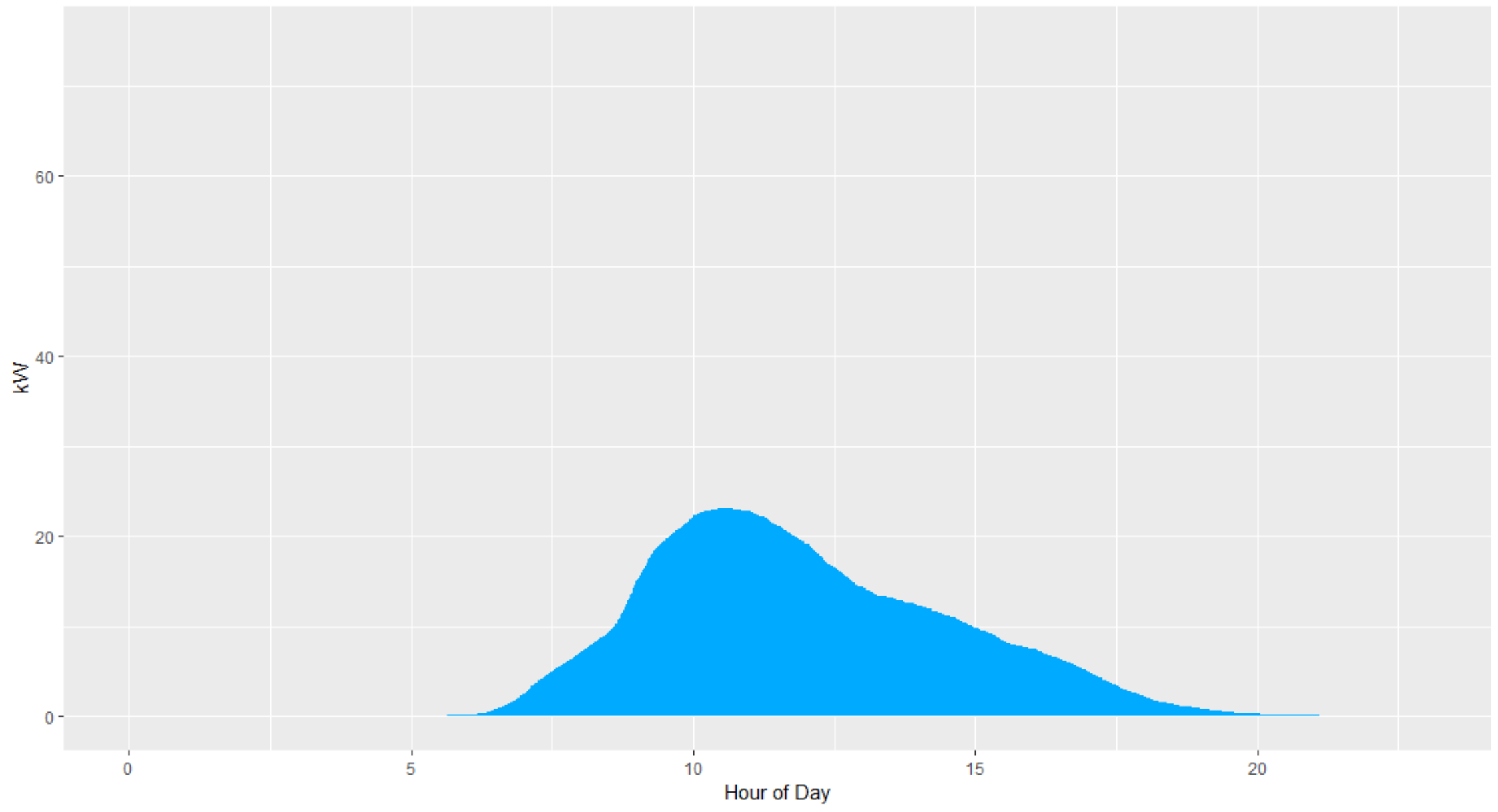

Figure 16. Average intraday power profile of all EVSE combined: COVID-19-influenced

Figure 16 is similar and has the same scale as Figure 15, but follows the onset of the COVID-19 pandemic. This shows the reduction caused by remote work that must be accounted for in any further analysis of the data. 


\section{Further Work}

Data will continue to be gathered as the workplace returns to normal or "new normal" over the coming months. Smart Charge Management (SCM) with utilize these data to mitigate peak load at NREL facilities. Research teams at NREL will also be using these data to better inform their assumptions for buildings, travel, and grid impacts. 


\section{References}

Bennett, Jesse. 2021. “Charging Infrastructure Technologies: Smart Electric Vehicle Charging for a Reliable and Resilient Grid (RECHARGE)." U.S. Department of Energy Vehicle Technologies Program 2021 Annual Merit Review and Peer Evaluation Meeting. https://www.energy.gov/sites/default/files/2021-06/elt202 bennett 2021 o 5$14752 \mathrm{pm}$ KS TM.pdf

Wickham, H. 2016. ggplot2: Elegant Graphics for Data Analysis. New York, NY: SpringerVerlag. 